\title{
El deber de sometimiento al procedimiento especial como limitación al recurso de protección ambiental (Corte Suprema)
}

\author{
Comentario de Francisco Pinilla Rodríguez*
}

Santiago, veintidós de mayo de dos mil catorce

"Décimo Quinto: Que sobre el particular y tal como se adelantó en el motivo octavo, la Conadi ha informado a fojas 336 ratificando lo obrado en su Ordinario $\mathrm{N}^{\circ} 57$ de 15 de marzo de 2013 , rolante a fojas 148 , oportunidad en la que manifestó su conformidad con el proyecto, toda vez que las distancias que median entre la planta de secado y compactado de cloruro de potasio y las comunidades indígenas de Peine y de Socaire son de 35 y 47 kilómetros, respectivamente; que respecto de la probable afectación que ésta ocasionaría al territorio ancestral y patrimonial atacameño, indica que no existen antecedentes ciertos y efectivos que permitan establecerla; y que no ha existido alteración de las aguas y tierras que los actores denuncian como afectadas, antecedentes que en opinión de esta Corte son más que suficientes para desvirtuar las alegaciones planteadas por los recurrentes y estimar que el proyecto "Ampliación Planta de Secado y Compactado de Cloruro de Potasio" no requería de un Estudio de Impacto Ambiental, por no concurrir a su respecto ninguno de los presupuestos exigidos por el artículo citado en la consideración que antecede.

Décimo Sexto: Que respecto de la última de las alegaciones vertidas por los actores en su recurso, consistente en no haberse consultado a los pueblos indígenas directamente afectados por el proyecto calificado como ambientalmente favorable, es necesario señalar, en primer término, que conforme fluye de la lectura del recurso intentando en autos, en especial de lo referido a fojas 74 , y de la publicación del proyecto respectivo en el Diario Oficial, con fecha 02 de enero de 2013, por el Servicio de Evaluación Ambiental, los recurrentes no obstante estar en pleno conocimiento de la tramitación ante la institucionalidad ambiental del proyecto presentado por S.Q.M. Salar S.A., ninguna gestión realizaron ante la Comisión de Evaluación Ambiental de la Región Antofagasta en orden a hacer valer su pretensiones pese a que el Sistema de Evaluación Ambiental contempla los mecanismos pertinentes para ello, limitándose a remitir sendas cartas a la Conadi y al Municipio de San Pedro de Atacama, de lo que se colige que mal pudieron tenerse en consideración sus planteamientos si los mismos no

* Abogado, Doctor en Derecho, relator del Tercer Tribunal Ambiental de Valdivia. 
fueron hechos valer en las instancias pertinentes estando los actores, como ya se dijo, en conocimiento de la tramitación del proyecto que consideran como causante de una afectación a sus intereses, impidiendo con ello que sus observaciones fueren tenidas en cuenta al momento de resolver.

Décimo Séptimo: Que a lo anterior se debe adicionar que conforme el artículo $6^{\circ}$ del Convenio $\mathrm{N}^{\circ} 169$ de la OIT, tal consulta es procedente cada vez que se prevean medidas legislativas o administrativas susceptibles de afectarles directamente, afectación que de acuerdo con lo dispuesto en el artículo $7^{\circ}$ del mismo Convenio se produce cuando se ven modificadas sus vidas, creencias, instituciones y bienestar espiritual, las tierras que ocupan o utilizan de alguna manera, y la posibilidad de controlar, en la medida de lo posible, su propio desarrollo económico, social y cultural, hipótesis que no se verifican en la especie, toda vez que como ya se expuso en el motivo Décimo Quinto no se vislumbra cómo el proyecto en cuestión pudiese afectar a las comunidades indígenas que accionaron por esta vía, no encontrándose esta Corte, en consecuencia, en posición de adoptar medida alguna tendiente a otorgar cautela a los recurrentes.

Décimo Octavo: Que de acuerdo con lo antes razonado no se ha acreditado en la especie la existencia de un acto ilegal que afecte la garantía constitucional consistente en el Derecho a vivir en un medio ambiente libre de contaminación, por lo que el mismo será rechazado en dicho capítulo”.

\section{Comentario}

Tras la vigencia de la Ley 20.600/2012 que crea los Tribunales Ambientales (LTA) y la entrada en funcionamiento de estos, en breve tiempo la Corte Suprema ha ido fijando criterios decidores respecto de la procedencia de los recursos de protección en el contexto de la garantía constitucional de vivir en un medio ambiente libre de contaminación ${ }^{1}$.

En el caso que nos proponemos comentar sobre el Recurso de Protección ambiental deducido en el caso Peine, la Corte Suprema no ha acogido aquella acción de protección que intentaba revisar la legalidad de resoluciones de calificación ambiental (RCA). El motivo del rechazo del recurso se debe a que los recurrentes no actuaron dentro del procedimiento administrativo que dio lugar a la Declaración de Impacto Ambiental ${ }^{2}$ (DIA).

${ }^{1}$ Así, en SCS de 14.08.2013 (Rol No 4200-2013) se revoca la sentencia de Corte de Apelaciones de Santiago, que declaró la inadmisibilidad del recurso de protección como la resolución que dio lugar a la reposición de dicha inadmisibilidad, solicitando que dicha Corte analice los requisitos de procedencia del recurso, aun coexistiendo la competencia del Tribunal ambiental. Por su parte, la SCS de 25.09. 2013 (Rol No 5339-2013) no acoge recurso de protección pues lo solicitado por los recurrentes fue acogido por la Corte de Apelaciones y requiere por su parte la ejecución y control mediante los mecanismos previstos en sede administrativa.

${ }^{2}$ Similar cuestión ocurre en SCS de 29.04.2014 (Rol No 2892-2014). 
La LTA desarrolla competencias para el acceso al contencioso administrativo de manera bastante particular y especializada. En el caso de reclamaciones contra RCA por parte de la ciudadanía, todo indicaría que quien recurra para ante los Tribunales Ambientales, debe haber participado previamente en los procedimientos administrati$\operatorname{vos}^{3}$. Respecto de quienes no hayan participado en tales procedimientos, pareciera ser lógico una eventual imposibilidad de interponer recursos administrativos y reclamación especial ante el Tribunal Ambiental. Así, para estos últimos el Recurso de Protección constituiría prácticamente la única acción para recurrir contra la RCA.

Sin embargo, y como pone en evidencia la sentencia, para el caso de quien recurra de protección, no habiendo participado en procedimientos de DIA (e incluso pudiendo ser extensivo a EIA) ¿podría esto último constituir un criterio de exclusión que condicione la legitimación activa para recurrir de protección?; lo anterior, máxime habiendo constancia en el expediente administrativo sobre la base de otras actuaciones por parte de los ciudadanos, lo que probaría el conocimiento -a lo menos presunto- de encontrarse desarrollando el procedimiento de DIA. Esta es una de las cuestiones que propone la sentencia en comento.

En la sentencia se da cuenta que los recurrentes tuvieron noticia del procedimiento en cuestión, pero no participaron en él. Este hecho supone que dichos recurrentes habrían descartado la vía idónea o especial para plantear observaciones al procedimiento. La sujeción a este procedimiento especial lleva aparejado que, ante la eventualidad que sus opiniones no sean consideradas, se discuta la legalidad, ya en vía de recursos administrativos especiales y, finalmente, mediante reclamación ante el Tribunal Ambiental competente. Así, en el caso citado, las observaciones -ahora en el recurso, pretensiones- de los recurrentes que no participaron en el procedimiento de DIA, y tras examen de la legalidad por parte de la Corte, no dan lugar a ilegalidades, tanto porque de la actividad no existen motivos aparentes que impliquen el sometimiento a un procedimiento de EIA, como además no existiría una afectación que prevé el Convenio 169. De ahí entonces que al no existir ilegalidad tampoco es posible definir una vulneración al derecho fundamental en cuestión.

De lo anterior se puede comprender el valor que otorga la sentencia al presunto conocimiento que cabría al recurrente de encontrarse desarrollándose un procedimiento administrativo de DIA. Este conocimiento presunto constituiría una omisión al deber de los ciudadanos a exponer sus intereses acerca del proyecto en cuestión bajo la instancia de participación. Así, en la medida que el ciudadano participe, se legitimaría el traslado de la discusión de la legalidad en atención precisa a las herramientas recursivas del sistema de la LBGMA. Por lo que en este supuesto, si el ciudadano participa, sus pretensiones se sustraen a dicha vía recursiva.

Ahora bien, si el ciudadano no participa, teniendo noticia del proyecto -al menos de manera presunta para la Corte-, limitaría su posibilidad de discutir la vulneración

${ }^{3}$ Ello se puede inferir según lo dispuesto en el artículo 29 inc. final LBGMA; sin perjuicio que se condicione a interpretar el artículo 20 LBGMA en una lógica negatoria. 
del derecho, a causa de la posible ilegalidad, en sede de Recurso de Protección. Pues para ello, como insistimos, en criterio de la Corte, debieron haberse realizado las actuaciones que da lugar el procedimiento administrativo especial. Pero también cabe considerar que en el supuesto en cuestión -y tal como mencionamos- los ciudadanos se encuentran excluidos de las vías recursivas especiales y, junto a la omisión de participación -constatado su presunto conocimiento-, de amparo constitucional de sus derechos.

En nuestra opinión, el sometimiento a las etapas de participación ciudadana no son obligatorias y excluyentes para la ciudadanía, sino, al contrario, son un medio más de transparencia y actuación democrática de las personas u organizaciones en la decisión administrativa.

Este procedimiento básicamente lo que intenta compatibilizar es el marco jurídico para una actividad o proyecto, a fin de que este minimice impactos ambientales y coordine los intereses públicos y de terceros que participen. No obstante, ello no puede implicar una oportunidad única para que los ciudadanos pongan en evidencia sus pretensiones. Es decir, el hecho que el procedimiento administrativo establezca dichas modalidades de participación especial no es un obstáculo que excluye el acceso a otras posibles vías de revisión o, eventualmente, suprimir una posible impugnación de terceros afectados. Tampoco puede interpretarse que el hecho de existir un presunto conocimiento del procedimiento por parte del recurrente implique una renuncia a un derecho que no se ha ejercido, como es del caso no acceder por vía de participación ciudadana.

La sentencia establece una doctrina que estaría - en nuestra opinión- destinada a otorgar coherencia a las instancias especiales de revisión de la legalidad de los actos. El hecho de otorgar valor al conocimiento presunto del recurrente incide en la necesidad que sus pretensiones se reconduzcan por medio de la especialidad e idoneidad del procedimiento de participación, a efectos de poner a resguardo por las vías recursivas apropiadas. Pero ello no puede obstar a restringir el acceso al Recurso de Protección, por quienes -como ya sabemos- optaron por no acceder al procedimiento de participación. Lo que sí puede parecer razonable es que el hecho de no participar -a sabiendas del procedimiento en curso- y luego recurrir de protección, da cuenta de una ausencia de urgencia del presunto derecho vulnerado. La cautela de derechos constitucionales por medio del Recurso de Protección se asienta precisamente en la conculcación de dichos derechos y la necesidad de una tutela judicial de urgencia.

Finalmente, todo indica que se debe distinguir entre concentrar la revisión de la legalidad por medio de los procedimientos especiales que provee la LBGMA y la LTA que implican las instancias recursivo-administrativas, y, luego así, el reclamo ante el Tribunal Ambiental y, otra situación, cuando lo que se intenta es obtener tutela para un derecho fundamental. Aspectos disímiles pero en donde no cabría limitar la tutela judicial de un derecho por no someterse a instancias especiales. Sobre todo cuando la participación es voluntaria y, por lo demás, la acción constitucional es sin perjuicio de otros derechos. 